Photochem Photobiol. 2015 November ; 91(6): 1444-1451. doi:10.1111/php.12521.

\title{
Epigenetically Enhanced Photodynamic Therapy (ePDT) is Superior to Conventional Photodynamic Therapy for Inducing Apoptosis in Cutaneous T-Cell Lymphoma
}

\author{
Katrin Agnes Salva ${ }^{1,{ }^{*}}$ and Gary S. Wood ${ }^{1,2}$ \\ ${ }^{1}$ University of Wisconsin, Department of Dermatology, Wisconsin Institutes for Medical Research, \\ Madison, WI, U.S.A. \\ ${ }^{2}$ VA Medical Center, Madison, WI, U.S.A.
}

\begin{abstract}
Conventional photodynamic therapy with aminolevulinate (ALA-PDT) selectively induces apoptosis in diseased cells and is highly effective for treating actinic keratoses. However, similar results are achieved only in a subset of patients with cutaneous T-cell lymphoma (CTCL). Our previous work shows that the apoptotic resistance of CTCL correlates with low expression of death receptors like FAS, and that methotrexate upregulates FAS by inhibiting the methylation of its promoter, acting as an epigenetic derepressor that restores the susceptibility of FAS-low CTCL to caspase 8-mediated apoptosis. Here, we demonstrate that methotrexate increases the response of CTCL to ALA-PDT, a concept we refer to as epigenetically enhanced PDT (ePDT). Multiple CTCL cell lines were subjected to conventional PDT versus $e$ PDT. Apoptotic biomarkers were analyzed in situ with multispectral imaging analysis of immunostained cells, a method that is quantitative and $5 \times$ more sensitive than standard immunohistology for antigen detection. Compared to conventional PDT or methotrexate alone, $e$ PDT led to significantly greater cell death in all CTCL cell lines tested by inducing greater activation of caspase 8-mediated extrinsic apoptosis. Upregulation of FAS and/or TRAIL pathway components was observed in different CTCL cell lines. These findings provide a rationale for clinical trials of $e$ PDT for CTCL.
\end{abstract}

\section{Graphical abstract}

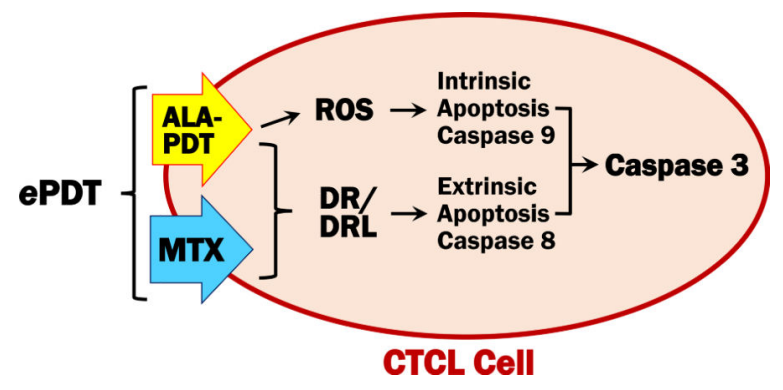

*Corresponding author's. ksalva@dermatology.wisc.edu (Katrin A. Salva). 


\section{INTRODUCTION}

Photodynamic therapy (PDT) utilizes the accumulation of a photosensitizer in diseased tissue and subsequent illumination with visible light. The resultant photochemical reaction leads to formation of reactive oxygen species (ROS), which destroy cells by inducing apoptosis and/or necrosis (1-3). In PDT with topical aminolevulinic acid (ALA), the targeted cells metabolize the porphyrin precursor ALA into the endogenous photosensitizer protoporphyrin IX (PpIX), rendering this treatment highly selective and virtually non-toxic (4). Conventional ALA-PDT represents a first-line therapy for actinic keratoses (AKs) and is increasingly used as an alternative therapeutic option for a wide range of skin disorders (57). Nevertheless, the excellent outcomes achieved in patients with AKs are not easily reproduced in other indications. This is exemplified by mycosis fungoides (MF), the most common form of cutaneous T-cell lymphoma (CTCL). Long-term complete responses to ALA-PDT were observed in up to 50\% of patients with patch/plaque MF in certain studies as well as in some cases of recalcitrant and/or tumor-stage disease (8-14). Such results are promising, however, the lack of success in many other cases of MF remains unexplained.

Epigenetic gene alterations, i.e. defective gene expression due to modifications other than those of DNA sequence, are recognized as crucial to the pathogenesis of disease (15). In CTCL, defects involving death receptor/ligand pairs such FAS/FASL, TNF-R1/TNFa and TRAIL-R2(DR5)/TNF-related apoptosis-inducing ligand (TRAIL) are correlated with resistance to apoptosis (16-18). Our previous work shows the interindividual heterogeneity of epigenetic alterations in CTCL, reflected in variable expression of apoptotic proteins such as FAS in lesional skin of MF patients (16). We have also demonstrated that methotrexate (MTX) acts as an epigenetic regulator by inhibiting gene promoter methylation, thus upregulating proteins that are essential to T-cell apoptosis and restoring the sensitivity of CTCL to apoptotic cell death $(19,20)$. Moreover, we established that multispectral imaging analysis (MIA) is $5 \times$ more sensitive in the detection of biomarkers in skin lesions as compared to standard light microscopy, making it ideally suited to preselect patients for targeted MTX therapy and to monitor protein changes in response to treatment (21). Therefore, we hypothesize that the limited response of CTCL to ALA-PDT might be due to epigenetically suppressed expression of death receptors and/or their ligands and that MTX increases the efficacy of PDT by enhancing extrinsic apoptosis (Figure 1). The data presented here support our theory, showing that the epigenetic action of MTX in concert with PDT allowed significantly greater induction of extrinsic apoptotic cell death as compared to conventional PDT. We propose to introduce epigenetically enhanced PDT $(e$ PDT $)$ as a novel treatment concept for disorders which require the eradication of malignant and/or activated T-lymphocytes.

\section{MATERIALS AND METHODS}

\section{Cell Lines}

The human CTCL cell lines MyLa, Hut78, HH, SZ4 and SeAx were acquired as described previously $(19,20)$. The cells were cultured in RPMI 1640 medium with 2mM L-glutamine, $10 \%$ fetal bovine serum, and $1 \mathrm{mM}$ sodium pyruvate (all cell lines) as well as $10 \mathrm{mM} 4-(2-$ hydroxyethyl)-1-piperazine-ethanesulfonic acid was added to the media (HH and SZ4 only). 


\section{Conventional PDT and ePDT}

For conventional PDT, cells were incubated for 6 hours with 1mM 5-aminolevulinic acid hydrochloride (Sigma-Aldrich, Saint Louis, MO), followed by exposure to $630 \mathrm{~nm}$ light at $3.22 \mathrm{~J} / \mathrm{cm}^{2}$ using the Luzchem Expo Panel light source equipped with a red filter (Luzchem Research, Ottawa, Canada) and collection at various time points post irradiation. For $e$ PDT, cells were treated with methotrexate hydrate (Sigma-Aldrich) for 48 hours and subjected to ALA-PDT as described above. ALA only, light only, MTX only, and untreated controls were included in all studies. Experiments involving ALA were performed in the dark to avoid photobleaching.

\section{Western blotting}

Cells were washed with ice-cold phosphate-buffered saline (PBS) and lysed with radioimmunoprecipitation assay buffer. DC Protein Assay (Bio-Rad, Hercules, CA) was

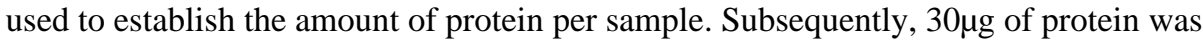
subjected to sodium dodecyl sulphate-polyacrylamide gel electrophoresis and transferred onto a nitrocellulose membrane. Blots were exposed to primary and secondary antibodies (anti-PARP polyclonal Ab, anti-FAS mAb clone $\mathrm{C} 18 \mathrm{C} 12$, anti-rabbit IgG horseradish peroxidase-linked Ab, all from Cell Signaling, Danvers, MA) followed by chemiluminescent detection.

\section{Immunohistochemistry (IHC)}

Cells were washed with PBS, centrifuged and re-suspended in PBS to create cytopreparations on glass slides, which were exposed to the following primary antibodies: anti-FAS/CD95 antibody clone DX2 (Enzo Life Sciences, Farmingdale, NY), anti-FASL antibody clone G247-4 (BD Pharmingen San Jose, CA), anti-cleaved caspase-3 antibody clone 5A1E (Cell Signaling), anti-DR4 polyclonal antibody sc-6823 (Santa Cruz Biotechnology, Dallas, TX), anti-TRAIL antibody clone III6F (Enzo Life Sciences), anticleaved caspase-8 antibody clone 12F5 (Enzo Life Sciences), and anti-cleaved caspase-9 antibody clone Asp330 (Cell Signaling). Proteins were visualized using the MACH4 Universal HRP-Polymer detection system (Biocare Medical, Concord, CA) and 3,3diaminobenzidine (DAB). All slides were counterstained with methylene blue (MB).

\section{Multispectral imaging analysis (MIA)}

The quantitative analysis of protein expression was carried out using the Nuance system (Perkin-Elmer, Waltham, MA). Multispectral 8-bit image cubes of relevant areas on each slide were acquired in brightfield mode at $20 \mathrm{~nm}$ intervals from 420 to $720 \mathrm{~nm}$, using a $20 \times$ objective lens and $1 \times 1$ binning. A spectral library containing the characteristic wavelength emission curves of $\mathrm{MB}$ and $\mathrm{DAB}$ was created by sampling pure spectra from slides stained with single dyes, i.e. $\mathrm{MB}$ only and $\mathrm{DAB}$ only. Blue and red pseudo-colors were assigned to visualize $\mathrm{MB}$ and $\mathrm{DAB}$, respectively. The image cubes, initially shown as pseudo-color composites of both blue and red, were unmixed into individual components by the Nuance 3.0.0 software version. For quantitation of protein expression, 100-300 cells per slide were manually designated as regions of interest (ROIs). Using the spectral library as reference, the system measured the amount of target signal (intensity of red pseudo-color) within each 
ROI, automatically converting spectral data into optical density (OD) units. Final data are displayed as average OD/cell. All histograms shown in Figures 3-7 are based on the quantitative assessment of protein expression by MIA. Exemplary MIA-generated highpower images of protein expression and quantitative analysis are shown in Figure 2.

\section{Quantitation of PpIX}

cells were cultured and incubated with 5-ALA as described above. After 6 hours of incubation time, the cells were centrifuged, re-suspended in PBS and placed on glass slides for immediate capture of PpIX fluorescence with the Nuance microscope. Multispectral images cubes were acquired in fluorescence mode using a $405 \mathrm{~nm}$ light source, 20x objective lens and $1 \times 1$ binning. The characteristic brick-red fluorescence of PpIX was captured to build the PpIX spectral library, which was subsequently used to quantitate intracellular PpIX as outlined above. Final data were displayed as average signal/cell.

\section{Statistical analysis}

Statistical analysis was performed by using Student's t-test. P-values $<0.01$ were considered statistically significant.

\section{RESULTS}

\section{The response of CTCL cell lines to conventional PDT is positively correlated with baseline expression of FAS}

The CTCL cell lines used throughout our studies are characterized by known FAS gene abnormalities, resulting in a wide range of FAS protein expression with complete absence of FAS gene in SeAx cells $(16,22)$. Conventional ALA-PDT caused caspase 3 cleavage in all cell lines, peaking at 24-48 hours (Figure 3A). However, the FAS-high prototypes MyLa and Hut78 demonstrated significantly greater cleaved caspase 3 levels than their FAS-low (HH, SZ4) and FAS-null (SeAx) counterparts. Figure 3B,C shows that there was an approximately 10-fold increase in intracellular PpIX levels following incubation with ALA. Notably, PpIX accumulation following ALA incubation did not differ significantly among cell lines, thus excluding inadequate ALA-uptake and/or insufficient PpIX formation as a possible cause of differences in response to ALA-PDT. These data mirror the variable response of CTCL to PDT encountered in the clinical setting, and indicate a positive correlation between baseline FAS levels and ALA-PDT-induced apoptosis.

\section{ePDT upregulates both FAS/CD95 and FASL in CTCL}

Conventional PDT did not significantly affect FAS expression in any of the cell lines tested (Figure 4A). In contrast, both MTX alone as well as $e$ PDT resulted in a 3- and 4-fold increase of FAS in FAS-low prototypes $\mathrm{HH}$ and SZ4, respectively. This effect was achieved at very low doses of MTX, as demonstrated in Figure 4B. The baseline levels of FASL were relatively low in all cell lines, and remained unchanged after MTX treatment (Figure 5). Conventional PDT led to a 2-3-fold FASL upregulation of FASL across all cell lines as compared to untreated controls. Moreover, $e$ PDT resulted in significantly greater FASL increase as compared to ALA-PDT in MyLa, Hut78 and SZ4 cells. Taken together, these 
data demonstrate that unlike conventional PDT or MTX alone, $e$ PDT restores FAS expression in FAS-low cell lines while simultaneously upregulating FASL.

ePDT increases TRAIL-R1(DR4)/TRAIL in CTCL

The baseline levels of DR4 were low in all CTCL cell lines, and were significantly increased by both components of $e$ PDT (predominantly by MTX and to a lesser degree by PDT) in 4 of the cell lines tested (Figure 6A). In Hut78 cells, the increase in DR4 was observed following MTX but not conventional PDT. Consequently, $e$ PDT resulted in greater DR4 increase as compared to conventional PDT in all cell lines (Figure 6A). Figure 6B shows baseline TRAIL levels as measured by MIA, revealing high-medium levels in SZ4 and MyLa cells, and very low levels in the remaining three cell lines. MTX alone resulted in upregulation of TRAIL only in MyLa cells, while conventional PDT led to TRAIL increase only in HH cells. Whereas $e$ PDT led to TRAIL upregulation in both MyLa and HH cells, TRAIL expression was significantly higher post $e$ PDT versus conventional PDT only in MyLa cells. These findings underscore the involvement of multiple death receptor/ligand pairs in the response of CTCL to $e$ PDT. Table 1 summarizes the changes in FAS/FASL and DR4/TRAIL expression in response to the individual components of $e$ PDT, namely MTX and PDT.

\section{ePDT induces greater apoptosis than conventional PDT in CTCL}

Compared to conventional PDT, $e$ PDT resulted in greater apoptosis in all cell lines as evidenced by caspase 3 cleavage post treatment (Figure 7A). The most pronounced increase in apoptotic cell death following $e$ PDT versus conventional PDT was observed in the FAS low cell lines HH and SZ4. Figures 7B and 7C depict the effects of $e$ PDT versus conventional PDT in HH cells in greater detail, showing that $e$ PDT with low-dose MTX elicited significantly greater cleavage of caspase 3 as well as PARP.

\section{ePDT enhances predominantly the extrinsic apoptotic signaling in CTCL}

As demonstrated in Figure 8A, $e$ PDT produced significantly greater caspase 8 activation as compared to MTX alone as well as to conventional PDT in all cell lines. These data suggest that the $e$ PDT-induced increases in FAS/FASL and DR4/TRAIL summarized in Table 1 are positively correlated with the capability of malignant T-cells to undergo extrinsic apoptosis. Figure 8B shows that $e \mathrm{PDT}$ also resulted in greater caspase 9 activation in three cell lines, further enhancing the overall greater efficacy of this treatment as compared to PDT or MTX alone.

\section{DISCUSSION}

There are no curative treatment options for MF and its leukemic variant, Sézary syndrome (SS), both of which represent $>75 \%$ of all CTCLs. Recently developed therapies include antibody-drug conjugates which target specific markers expressed primarily on the surface of lymphoma cells $(23,24)$. However, the indolent nature of early-stage MF precludes aggressive systemic approaches. Consequently, there is an urgent need for effective yet nontoxic treatment strategies for refractory early-stage CTCL. 
Unpredictable clinical outcomes despite optimized drug and light delivery continue to represent a major drawback of ALA-PDT. The current trend is therefore its combined use with other therapies. Pretreatment of basal cell carcinomas with retinoids was found to enhance the efficacy of ALA-PDT (25), but equivalent trials in patients with CTCL are lacking. In the CTCL cell line Hut78, a combination of 8-methoxy-psoralen and ALA followed by UVA irradiation was superior to either conventional PUVA or PDT alone (26). However, UVA is carcinogenic and penetrates skin far less deeply $(1 \mathrm{~mm})$ than red light (up to $5 \mathrm{~mm}$ ) (4). This may be the reason why MF patients who receive PUVA, UVA1 or narrow band UVB therapy require at least 15-20 treatments, while PDT usually achieves comparable results with far fewer sessions (13).

Very few studies explore the mechanisms of ALA-PDT-induced apoptosis in activated and/or malignant $\mathrm{T}$ lymphocytes. Involvement of death receptor/ligand pairs in PDTinduced apoptosis has been demonstrated in the setting of PDT with Pc4, Calphostin-C, hypocrellin and hypericin (27-30), but not in that of ALA-PDT and CTCL. ALA-PDT induces apoptosis predominantly via the intrinsic pathway due to preferential localization of PpIX in the mitochondria, however, exogenous ALA administration also leads to PpIX accumulation in cellular membranes and in the cytosol (31-33). In the oral cancer cell line Ca9-22, ALA-PDT activated both caspase 8 and caspase 9 via the NF- $\kappa B / J N K$ pathway, whereas p38 MAPK and JNKs were involved in the initiation of ALA-PDT-mediated apoptosis in non-small cell lung carcinoma cells $(34,35)$. Interestingly, the first report of PDT-induced apoptosis in a malignant T-cell line featured ALA-PDT (36). Subsequent studies on leukemia/lymphoma cells with photosensitizers other than ALA confirmed the susceptibility of T cells to PDT-induced apoptosis (2, 37-41). Notably, the majority of research involving the response of malignant or activated T-cells to PDT has been conducted on Jurkat cells, a cell line derived from T-cell acute lymphoblastic leukemia, which is clinically very different from CTCL and therefore not at all representative of MF/SS with regard to its tumor biology $(36,42)$. In contrast, the spectrum of human CTCL cell lines studied here encompasses a wide range of phenotypes in terms of death receptor/ligand expression, allowing us to study the associations between varying levels of these proteins in CTCL and the efficacy of MTX, PDT and $e$ PDT.

The proposed mechanisms underlying the efficacy of $e \mathrm{PDT}$ are depicted schematically in Figure 1. Figure 1A shows a lymphoma cell with downregulated or absent expression of death receptor(s) such as FAS. The formation of ROS following conventional ALA-PDT induces apoptosis via the intrinsic caspase 9-mediated pathway. ROS activate numerous signaling pathways, such as the JNK/c-Jun pathway, which is known to upregulate some death receptor ligands (43). As summarized in Figure 1B, cells with fully functioning death receptor/ligand pairs or cells with MTX-mediated derepression of death receptors/ligands are more likely to undergo apoptosis after PDT for the following reasons: 1) death receptor/ ligand binding boosts an additional cell death mechanism, the extrinsic apoptotic pathway $(19,20), 2)$ increased caspase 8 cleavage leads to Bid truncation, which in turn boosts the intrinsic apoptotic pathway (44), 3) MTX leads to increased production of ROS (45), further contributing to caspase 9 activation. 
The data presented in Figures 3-8 support the above concept, demonstrating significantly greater activation of apoptosis primarily via the extrinsic pathway as well as by increased cleaved caspase 3 and PARP cleavage products in $e$ PDT as compared to PDT or MTX alone. The expression of FAS in CTCL was unaffected by PDT. These findings are in line with a previous report that showed no change in FAS levels in Jurkat cells after PDT (41). Our observation that ALA-PDT increases FASL in CTCL constitutes another novel finding in this setting, albeit one that was anticipated, since ROS such as $\mathrm{H}_{2} \mathrm{O}_{2}$ and singlet oxygen are major known upregulators of FASL in activated T-lymphocytes $(46,47)$. Since MTX increased FAS levels in FAS-low cell lines, $e$ PDT created the ideal prerequisite for FAS/ FASL engagement irrespective of baseline protein levels, correlating with increased activation of the extrinsic pathway. $e$ PDT surpassed the efficacy of conventional PDT even in FAS-high cell lines, and resulted in increased cleaved caspase 8 levels in FAS-null SeAx cells, indicating the involvement of other death receptor/ligand pairs as well as additional mechanisms in the response of CTCL to $e$ PDT. All five cell lines studied here showed a low baseline level of DR4. MyLa and SZ4 were TRAIL-high, whereas the remaining cell lines exhibited low TRAIL baseline levels. MTX increased DR4 in all cell lines and upregulated TRAIL in MyLa cells, while PDT led to increased DR4 levels in MyLa, HH, SZ4 and SeAx and increased TRAIL in HH cells. Taken together, the above data support the hypothesis that multiple death receptor/ligand pairs contribute to the enhanced extrinsic apoptosis observed in $e$ PDT. Future studies are planned to investigate whether these effects are due to decreased methylation of DR4 and/or TRAIL promoter by MTX. MTX also exerts effects that are independent of its function as an epigenetic regulator, e.g. S-phase inhibition of mitosis. In addition, it has been shown that MTX promotes cellular differentiation and increases intracellular PpIX in epithelial cancers by upregulation of coproporphyrinogen III (CPIII) oxidase, the enzyme that catalyzes the oxidative decarboxylation of CPIII to PpIX $(48,49)$. Both ALA-PDT and MTX are well-known and approved treatment modalities. The concept of $e$ PDT could therefore be tested in clinical trials without further need for in vitroor animal studies. In addition to oral dosing of MTX, this work might also prompt the formulation of MTX as a topical drug. MIA-based quantitative IHC lends itself as an excellent tool to a) pre-select the patients who would most likely benefit from $e \mathrm{PDT}$ and b) monitor the effects of $e$ PDT by objective measurements of pertinent proteins directly in skin biopsies $(19,23,50,51)$. By employing $e$ PDT in this way, the success of traditional ALAPDT seen in AKs could be potentially replicated in CTCL. $e$ PDT would also represent a non-carcinogenic alternative to radiation therapy in cases of facial and/or limited extent CTCL. Lastly, the applications of this novel modality extend well beyond CTCL: 1) we expect $e$ PDT to exert therapeutic effects in cutaneous disorders in which activated T-cells play a central role, such as psoriasis, and 2) epigenetic dysregulation is a hallmark of other skin cancers as well, all of which represent targets for future studies and potential candidates for $e$ PDT.

\section{ACKNOWLEDGEMENTS}

This study was supported in part by Merit Review funding from the Department of Veterans Affairs (G.S. Wood) and the NIH T32AR055893 grant (K.A. Salva). 


\section{REFERENCES}

1. Henderson BW, Dougherty TJ. How does photodynamic therapy work? Photochem Photobiol. 1992; 55:145-157. [PubMed: 1603846]

2. Agarwal ML, Clay ME, Harvey EJ, Evans HH, Antunez AR, Oleinick NL. Photodynamic therapy induces rapid cell death by apoptosis in L5178Y mouse lymphoma cells. Cancer Res. 1991; 51:5993-5996. [PubMed: 1933862]

3. Ahmad N, Feyes DK, Agarwal R, Mukhtar H. Photodynamic therapy results in induction of WAF1/ CIP1P21 leading to cell cycle arrest and apoptosis. Proc. Natl. Acad. Sci. 1998; 95:6977-6982. [PubMed: 9618524]

4. Kennedy JC, Pottier RH, Pross DC. Photodynamic therapy with endogenous protoporphyrin IX: basic principles and present clinical experience. J. Photochem. Photobiol. B. 1990; 14:275-292. [PubMed: 1403373]

5. Bissonnette R, Lui H. Current status of photodynamic therapy in dermatology. Dermatol. Clin. 1997; 15:507-519. [PubMed: 9189686]

6. Salva K. Photodynamic therapy: unapproved uses, dosages or indications. Clin. Dermatol. 2002; 20:571-581. [PubMed: 12435528]

7. Wan MT, Lin JY. Current evidence and applications of photodynamic therapy in dermatology. Clin. Cosmet. Investig. Dermatol. 2014; 7:145-163.

8. Wolf P, Fink-Puches R, Cerroni L, Kerl H. Photodynamic therapy for mycosis fungoides after topical photosensitization with 5-aminolevulinic acid. J. Am. Acad. Dermatol. 1994; 31:678-680. [PubMed: 8089302]

9. Edstrom DW, Ross AM, Parvit A. Topical 5-aminolevulinic acid-based photodynamic therapy for mycosis fungoides - a study of cell proliferation and apoptosis before and after therapy. J. Dermatol. Sci. 1998; 16:229.

10. Coors EA, von den Driesch P. Topical photodynamic therapy for patients with therapy-resistant lesions of cutaneous T-cell lymphoma. J. Am. Acad. Dermatol. 2004; 50:363-367. [PubMed: 14988676]

11. Edstrom DW, Hedblad MA. Long-term follow-up of photodynamic therapy for mycosis fungoides. Acta Derm. Venereol. 2008; 88:288-290. [PubMed: 18480938]

12. Fernandez-Guarino M, Harto A, Perez-Garcia B, Montull C, De Las Heras E, Jaén P. Plaque-phase mycosis fungoides treated with photodynamic therapy: results from 12 patients. Actas Dermosifiliogr. 2010; 101:785-791. [PubMed: 21034709]

13. Kim ST, Dang DY, Kang JS, Baek JW, Jeon YS, Suhet KS. Photodynamic therapy with methylaminolevulinic acid for mycosis fungoides. Acta. Derm. Venereol. 2012; 92:264-268. [PubMed: 22170261]

14. Hasson A, Navarrete-Dechent C, Nicklas C, Sazunic I. Topical photodynamic therapy with 5aminolevulinate for the treatment of tumor-stage mycosis fungoides: a case report. Int. J. Dermatol. 2013; 52:1535-1537. [PubMed: 24134456]

15. Bonazzi VF, Irwin D, Hayward NK. Identification of candidate tumor suppressor genes inactivated by promoter methylation in melanoma. Genes Chromosomes Cancer. 2009; 48:10-21. [PubMed: 18803327]

16. Stutz N, Johnson RD, Wood GS. The Fas apoptotic pathway in cutaneous T-cell lymphomas: frequent expression of phenotypes associated with resistance to apoptosis. J. Am. Acad. Dermatol. 2012; 67:1327. [PubMed: 22884443]

17. Braun FK, Fecker LF, Schwarz C, Walden P, Assaf C, Duerkop H, Sterry W, Eberle J. Blockade of death receptor-mediated pathways early in the signaling cascade coincides with distinct apoptosis resistance in cutaneous T-cell lymphoma cells. J. Invest. Dermatol. 2007; 127:2425-2437. [PubMed: 17495957]

18. Contassot E, Kerl K, Roques S, Shane R, Gaide O, Dupuis M, Rook AH, French LE. Resistance to FasL and tumor necrosis factor-related apoptosis-inducing ligand-mediated apoptosis in Sezary syndrome T-cells associated with impaired death receptor and FLICE-inhibitory protein expression. Blood. 2008; 111:4780-4787. [PubMed: 18314443] 
19. Wu J, Nihal M, Siddiqui J, Vonderheid EC, Wood GS. Low FAS/CD95 expression by CTCL correlates with reduced sensitivity to apoptosis that can be restored by FAS upregulation. J. Invest. Dermatol. 2009; 129:1165-1173. [PubMed: 18923451]

20. Wu J, Wood GS. Reduction of Fas/CD95 promoter methylation, upregulation of Fas protein, and enhancement of sensitivity to apoptosis in cutaneous T-cell lymphoma. Arch. Dermatol. 2011; 147:443-450. [PubMed: 21173302]

21. Salva KA, Wu J, Nihal M, Wood GS. Analysis of protein expression in situ using multi-spectral imaging is superior to conventional immunohistochemistry (IHC): a new paradigm for patient selection for targeted therapy. J. Invest. Dermatol. 2013; 133(S):169.

22. Wu J, Siddiqui J, Nihal M, Vonderheid EC, Wood GS. Structural alterations of the FAS gene in cutaneous T-cell lymphoma (CTCL). Arch. Biochem. Biophys. 2011; 508:185-191. [PubMed: 21036138]

23. Krathen M, Bashey S, Sutherland K, Sundram U, Nagpal S, Salva K, Wood G, Advani R, Hoppe RH, Reddy S, Pulitzer M, Horwitz S, Kim YH. Brentuximab Vedotin Demonstrates Significant Clinical Activity in Relapsed or Refractory Mycosis Fungoides. Blood. 2012; 120:797.

24. Gandhi MD, Andrew ME, Fenske TS, Hamlin P, Coiffier B, Engert A, Moskovitz AJ, Ghosh N, Petrich AM, Lomasney J, Chadburn A, Wood GS, Salva KA, Nardone B, Trifilio SM, Raisch DW, West DP, Gordon LI, Winter JN. Pancreatitis in patients treated with brentuximab vedotin: a previously unrecognized serious adverse event. Blood. 2014; 123:2895-2897. [PubMed: 24786458]

25. Lin MH, Lee JY, Ou CY, Wong TW. Sequential systemic retinoid and photodynamic therapy for multiple keratotic pigmented nodular basal cell carcinomas on the scalp. J. Dermatol. 2009; 36:518-521. [PubMed: 19712282]

26. Akita Y, Watanabe D, Yanagishita T, Kuhara T, Kawamura C, Masuda Y, Kawada M, Nakaseko $\mathrm{H}$, Tamada Y, Matsumoto Y. The effect of psoralen plus ultraviolet A in vitro in HUT-78 enhances by 5-aminolevulinic acid. Photodermatol. Photoimmunol. Photomed. 2007; 23:95-97. [PubMed: 17523931]

27. Ahmad N, Gupta S, Feyes DK, Mukhtar H. Involvement of Fas (APO-1/CD95) during photodynamic therapy-mediated apoptosis in human epidermoid carcinoma A431 cells. J. Invest. Dermatol. 2000; 115:1041-1046. [PubMed: 11121139]

28. Ali SM, Chee SK, Yuen GY, Olivo M. Photodynamic therapy induced Fas-mediated apoptosis in human carcinoma cells. Int. J. Mol. Med. 2002; 9:257-270. [PubMed: 11836632]

29. Olivo M, Ali-Seyed M. Apoptosis-signalling mechnisms in human cancer cells induced by Calphostin-PDT. Int. J. Oncol. 2007; 30:537-548. [PubMed: 17273754]

30. Chen B, Roskams T, Xu Y, Agostinis P, De Witte PAM. Photodynamic therapy with hypericin induces vascular damage and apoptosis in the RIF-1 mouse tumor model. Int. J. Cancer. 2002; 98:284-290. [PubMed: 11857421]

31. Inoue H, Kajimoto Y, Shibata MA, Miyoshi N, Ogawa N, Miyatake SI, Otsuki Y, Kuroiwa T. Massive apoptotic cell death of human glioma cells via a mitochondrial pathway following 5aminolevulinic acid-mediated photodynamic therapy. J. Neurooncol. 2007; 83:223-231. [PubMed: 17245620]

32. Ji Z, Yang G, Vasovic V, Cunderlikova B, Suo Z, Nesland JM, Peng Q. Subcellular localization pattern of protoporphyrin IX is an important determinant for its photodynamic efficiency of human carcinoma and normal cell lines. J. Photochem. Photobiol. B. 2006; 84:213-220. [PubMed: 16709459]

33. Wachowska M, Muchowicz A, Firczuk M, Gabrysiak M, Winiarska M, Wańczyk M, Bojarczuk K, Golab J. Aminolevulinic acid as a prodrug in photodynamic therapy of cancer. Molecules. 2011; 16:4140-4164.

34. Chen HN, Liu CM, Yang H, Chou HY, Chiang CP, Kuoet MYP. 5-Aminolevulinic acid induces apoptosis via NF- $\kappa \mathrm{B} / \mathrm{JNK}$ pathway in human oral cancer Ca9-22 cells. J. Oral. Pathol. Med. 2011; 40:483-490. [PubMed: 21138480]

35. Wu RWK, Yow CMN, Wong CK, Lam YH. Photodynamic therapy (PDT) - initiation of apoptosis via activation of stress-activated p38 MAPK andJNK signal pathway in $\mathrm{H} 460$ cell lines. Photodiagnosis Photodyn. Ther. 2011; 8:254-263. [PubMed: 21864799] 
36. Gad F, Viau G, Boushira M, Bertrand R, Bissonnette R. Photodynamic therapy with 5aminolevulinic acid induces apoptosis and caspase activation in malignant T cells. J. Cutan. Med. Surg. 2001; 5:8-13. [PubMed: 11281435]

37. Granville DJ, Jiang H, McManus BM, Hunt DWC. Fas ligand and TRAIL augment the effect of photodynamic therapy on the induction of apoptosis in Jurkat cells. Int. Immunopharmacol. 2001; 1:1831-1840. [PubMed: 11562074]

38. Grebenova D, Cajthamlova H, Bartosova H, Marinov J, Klamovi H, Fuchs O, Hrkal Z. Selective destruction of leukemic cells by photo-activation of 5-aminolevulinic acid-induced protoporphyrin IX. J. Photochem. Photobiol. 1998; 47:74-81.

39. Lam M, Lee YJ, Deng M, Hsia AH, Morrissey KA, Yan C, Azzizudin K, Oleinick NL, McCormick TS, Cooper KD, Baron ED. Photodynamic therapy with the silicon phthalocyanine Pc4 induces apoptosis in mycosis fungoides and Sezary syndrome. Adv. Hematol. 2010; 2010:896161. [PubMed: 21197103]

40. Ke MS, Xue L, Feyes DK, Azizuddin K, Baron ED, McCormick TS, Mukhtar H, Panneerselvam A, Schluchter MD, Cooper KD, Oleinick NL, Stevens SR. Apoptosis mechanisms related to the increased sensitivity of Jurkat T-cells vs A431 epidermoid cells to photodynamic therapy with the phthalocyanine Pc4. Photochem Photobiol. 2008; 84:407-414. [PubMed: 18221452]

41. Jiang H, Granville DJ, North JR, Richter AM, Hunt DWC. Selective action of the photosensitizer QLT0074 on activated human T lymphocytes. Photochem Photobiol. 2002; 76:224-231. [PubMed: 12194221]

42. Furre IE, Moller MTN, Shahzidi S, Nesland JM, Peng Q. Involvement of both caspase-dependent and -independent pathways in apoptotic induction by hexaminolevulinate-mediated photodynamic therapy in human lymphoma cells. Apoptosis. 2006; 11:2031-2042. [PubMed: 17036199]

43. Kuntzen C, Sonuc N, De Toni EN, Opelz C, Mucha SR, Gerbes AL, Eichhorst ST. Inhibition of cJun-terminal-kinase sensitizes tumor cells to CD95-induced apoptosis and induces G2/M cell cycle arrest. Cancer Res. 2005; 65:6780-6788. [PubMed: 16061660]

44. Kantari C, Walczak H. Caspase- 8 and bid: caught in the act between death receptors and mitochondria. Biochim. Biophys. Acta. 2011; 1813:558-563. [PubMed: 21295084]

45. Phillips DC, Woollard KJ, Griffiths HR. The anti-inflammatory actions of methotrexate are critically dependent upon the production of reactive oxygen species. Br. J. Pharmacol. 2003; 138:501-511. [PubMed: 12569075]

46. Hildeman D. Regulation of T-cell apoptosis by reactive oxygen species. Free Radic. Biol. Med. 2004; 36:1496-1504. [PubMed: 15182852]

47. Hug H, Strand S, Grambihler A, Galle J, Hack V, Stremmel W, Krammer PH, Galle PR. Reactive oxygen intermediates are involved in the induction of CD95 ligand mRNA expression by cytostatic drugs in hepatoma cells. J. Biol. Chem. 1997; 272:28191-28193. [PubMed: 9353266]

48. Sinha AK, Anand S, Ortel BJ, Chang Y, Mai Z, Hasan T, Maytin EV. Methotrexate used in combination with aminolevulinic acid for photodynamic killing of prostate cancer cells. Br. J. Cancer. 2006; 95:485-495. [PubMed: 16868543]

49. Anand S, Honari G, Hasan T, Elson P, Maytin EV. Low-dose methotrexate enhances aminolevulinate-based photodynamic therapy in skin carcinoma cells in vitro and in vivo. Clin. Cancer Res. 2009; 15:3333-3343. [PubMed: 19447864]

50. Wu J, Salva KA, Stutz N, Longley BJ, Spiegelman VS, Wood GS. Quantitative gene analysis of methylation and expression (Q-GAME) in fresh or fixed cells and tissues. Exp. Dermatol. 2014; 23:304-309. [PubMed: 24646432]

51. Wu J, Salva KA, Wood GS. C-CBL E3 ubiquitin ligase is overexpressed in cutaneous T-cell lymphoma: its inhibition promotes activation-induced cell death. J. Invest. Dermatol. 2014 
A

PDT: ALA + Light
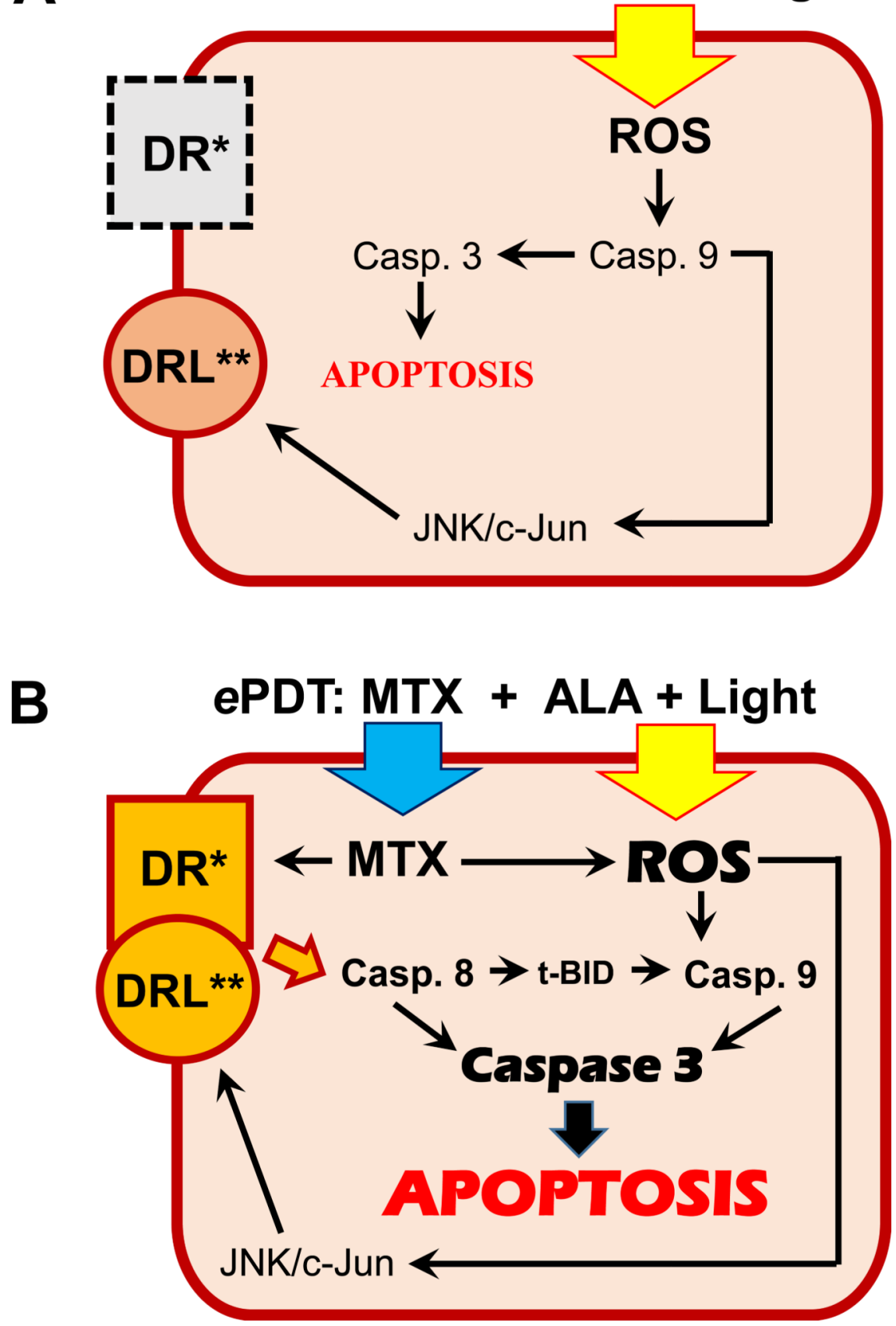

Figure 1.

A) Proposed response of CTCL cells with downregulated/absent expression of death receptors/ligands to conventional ALA-PDT. The generation of ROS by PDT triggers apoptosis via caspase 9 cleavage and activates pathways which are known to upregulate some death receptor ligands. B) Proposed response of CTCL cells to $e$ PDT. The binding of fully functional death receptors with their ligands triggers an additional apoptotic pathway, the extrinsic caspase 8-mediated pathway, which leads to enhanced apoptosis. See discussion for further details. 
*DR: death receptor, e.g. FAS, DR4; **DRL: death receptor ligand, e.g. FASL, TRAIL; MTX: methotrexate; ROS: reactive oxygen species; t-BID: truncated BH3 interactingdomain death agonist; JNK: Jun N-terminal kinase. 


\section{A HH Cells}

Routine IHC images of FAS (brown) and counterstain (blue)

MSI-generated images of FAS only, shown in user-assigned color red

Figure 2.

\section{Baseline FAS expression}
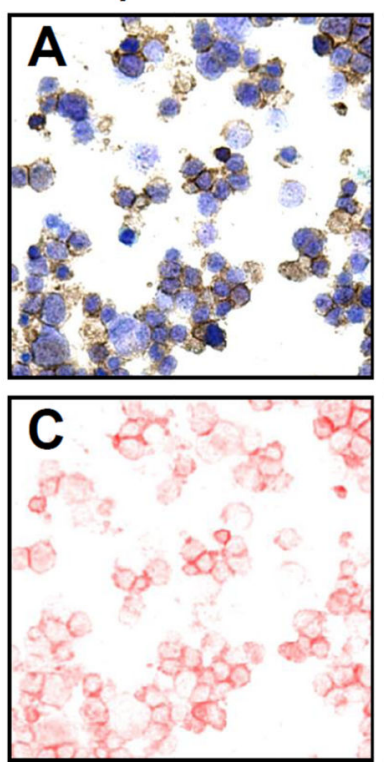

FAS expression post MTX
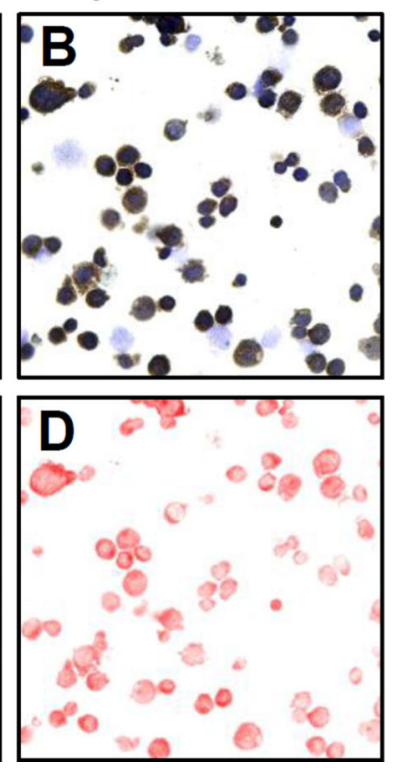

B

FAS, avg. OD/cell

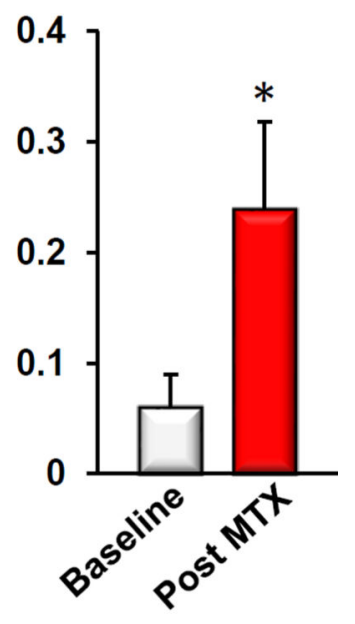

A) Example of protein quantitation using multispectral imaging. A and B: Routine immunohistochemical (IHC) images of prototypical FAS-low HH cells stained for FAS before (baseline) and after treatment with MTX. The brown chromogen represents FAS, whereas the blue stain visualizes cell nuclei. C and D: MIA-systems allow to unmix routine IHC images into individual components. Here, the color red was user-assigned to depict FAS expression, which is shown unmixed (without the blue counterstain) to visualize the full extent of the stain intensity. As outlined in detail in Materials and Methods, MIAgenerated images are then used to quantitatively assess protein expression. B) The histogram demonstrates FAS increase in HH cells in response to MTX (*p $<0.01$ as compared to untreated controls). The above described MIA-based quantitative assessment was used to generate all histograms shown in Figures 3-7. 


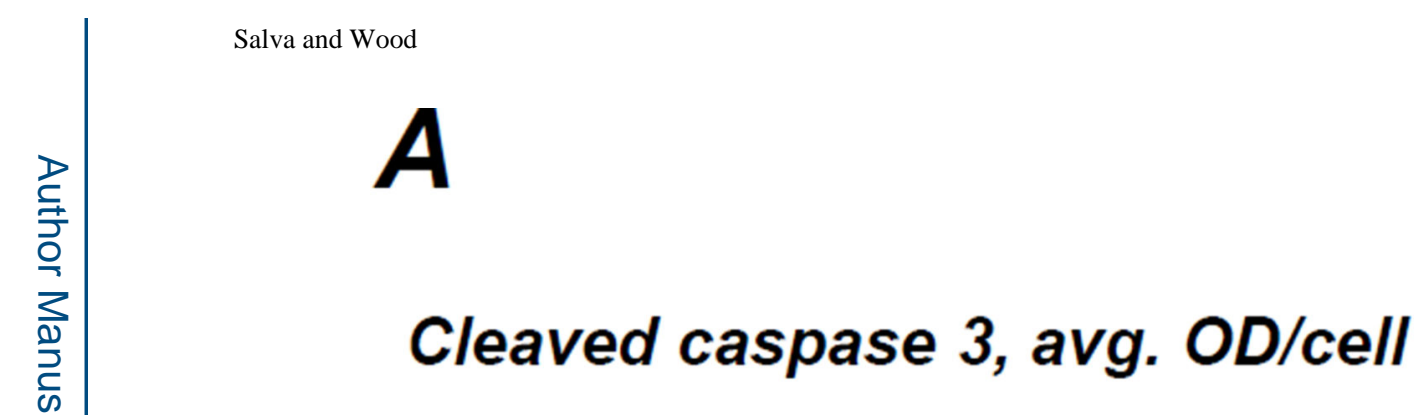

MyLa Hut78 HH SZ4 SeAx 0.4 * * *

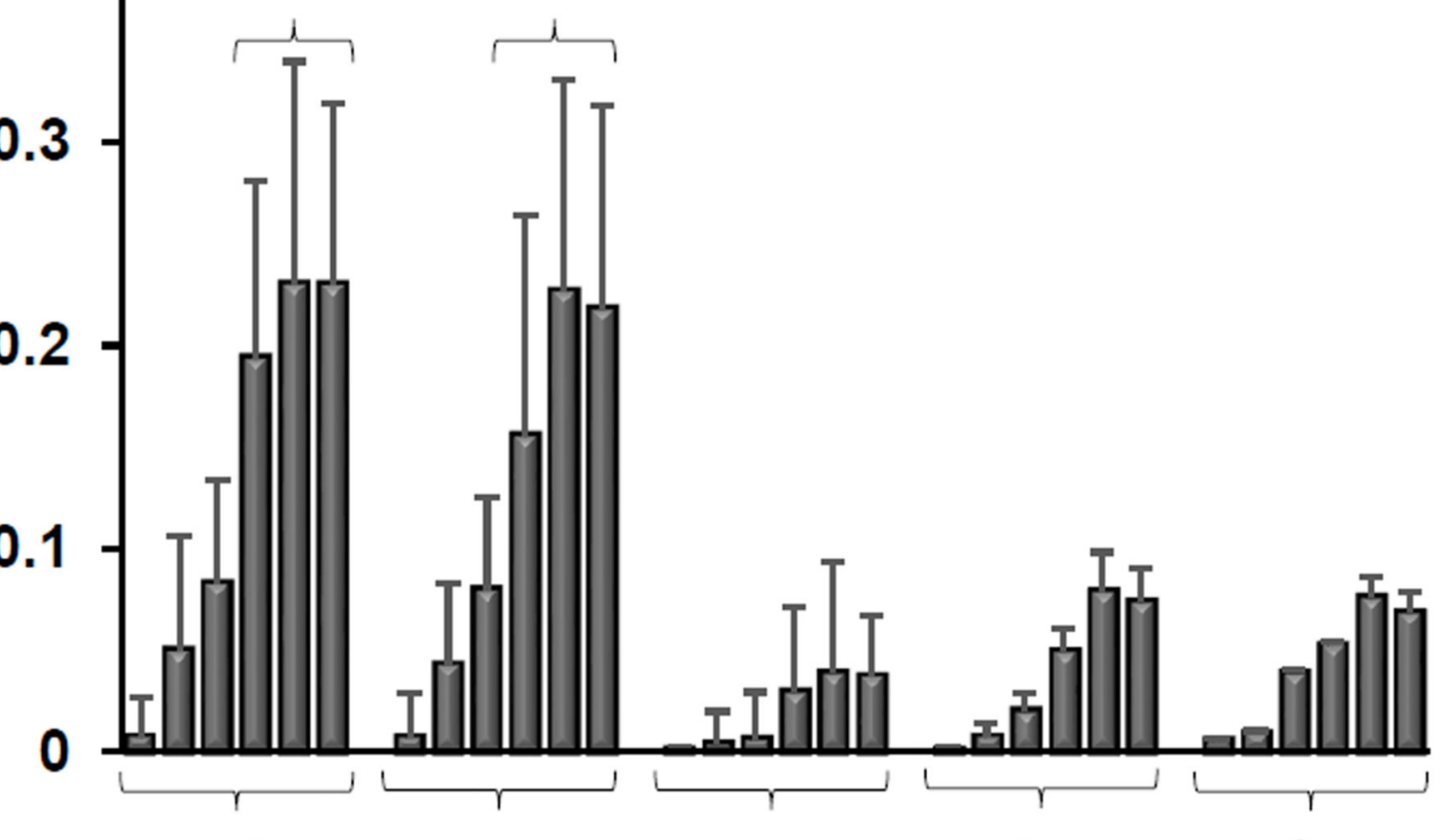

0.3

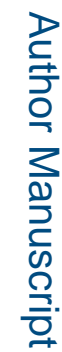

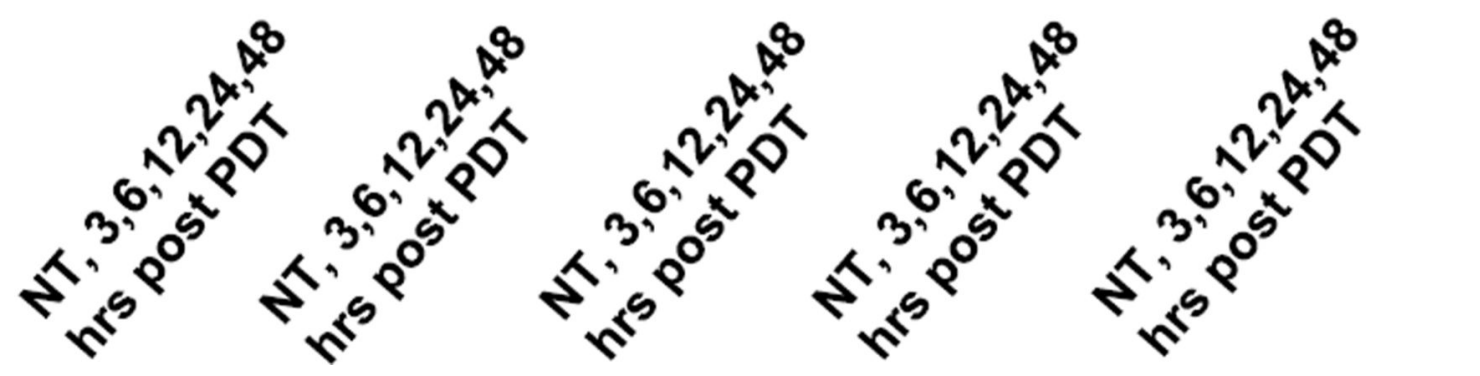




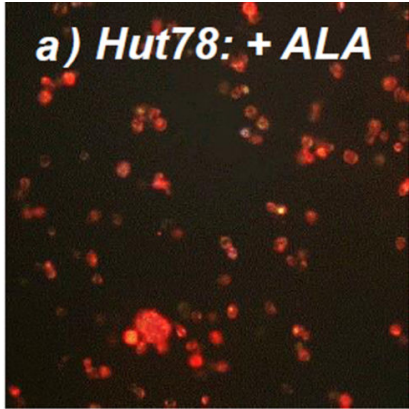

c) Hut78: - ALA

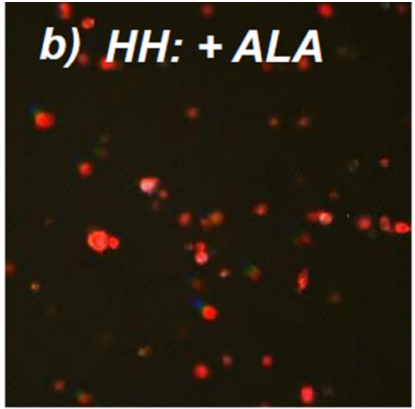

d) $H H$; - ALA:
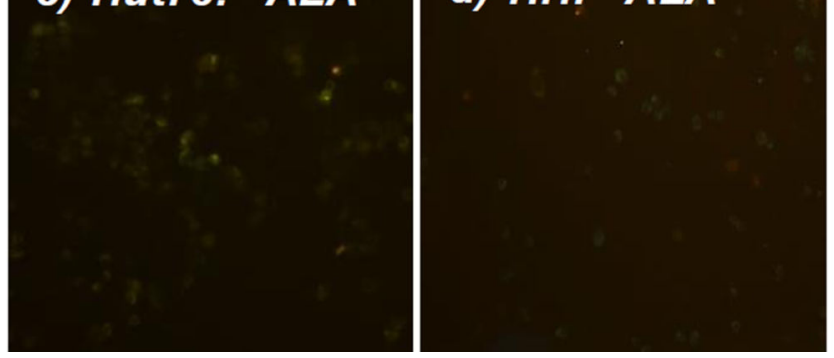
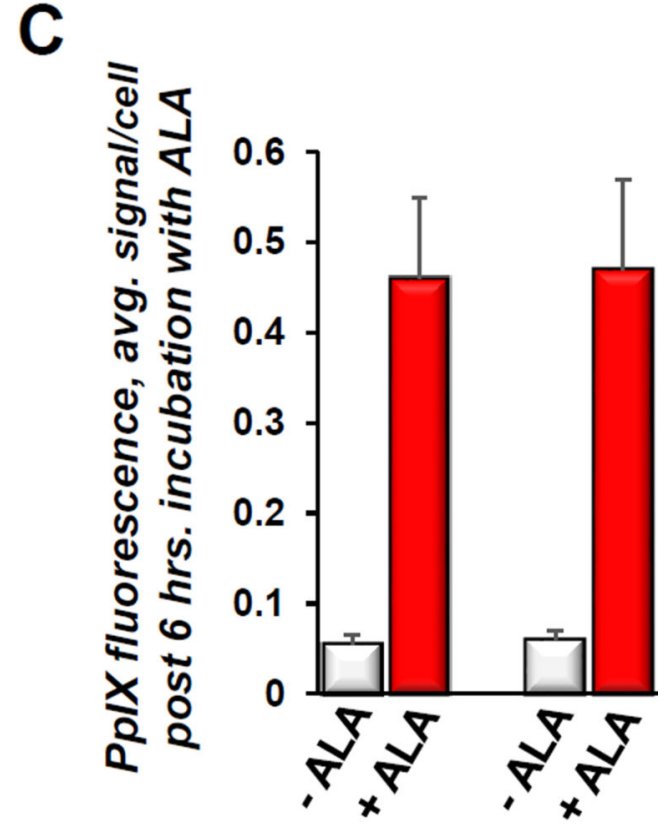

Figure 3.

A) Quantitative IHC using MIA of caspase 3 cleavage in CTCL cell lines following conventional ALA-PDT. Cells were collected at various time points post treatment, data for each cell line are shown as follows: untreated control, 3, 6, 12, 24 and 48 hours post PDT. $* \mathrm{p}<0.01$ as compared to caspase 3 activation in HH, SZ4 and SeAx cells. B) PpIX fluorescence (red) in prototypical FAS-high (a) and FAS-low (b) CTCL cell lines after incubation with ALA, $\mathrm{c}$ and d show respective untreated controls. C) The histogram shows quantitative MIA-based analysis of intracellular PpIX in Hut78 and HH cells before (ALA) and after (+ ALA) incubation with 1mM ALA for 6 hours (*p $<0.01$ as compared to untreated controls). All images and data shown in this as well as in the subsequent figures are representative of three separate experiments. 
A FAS, avg. OD/cell
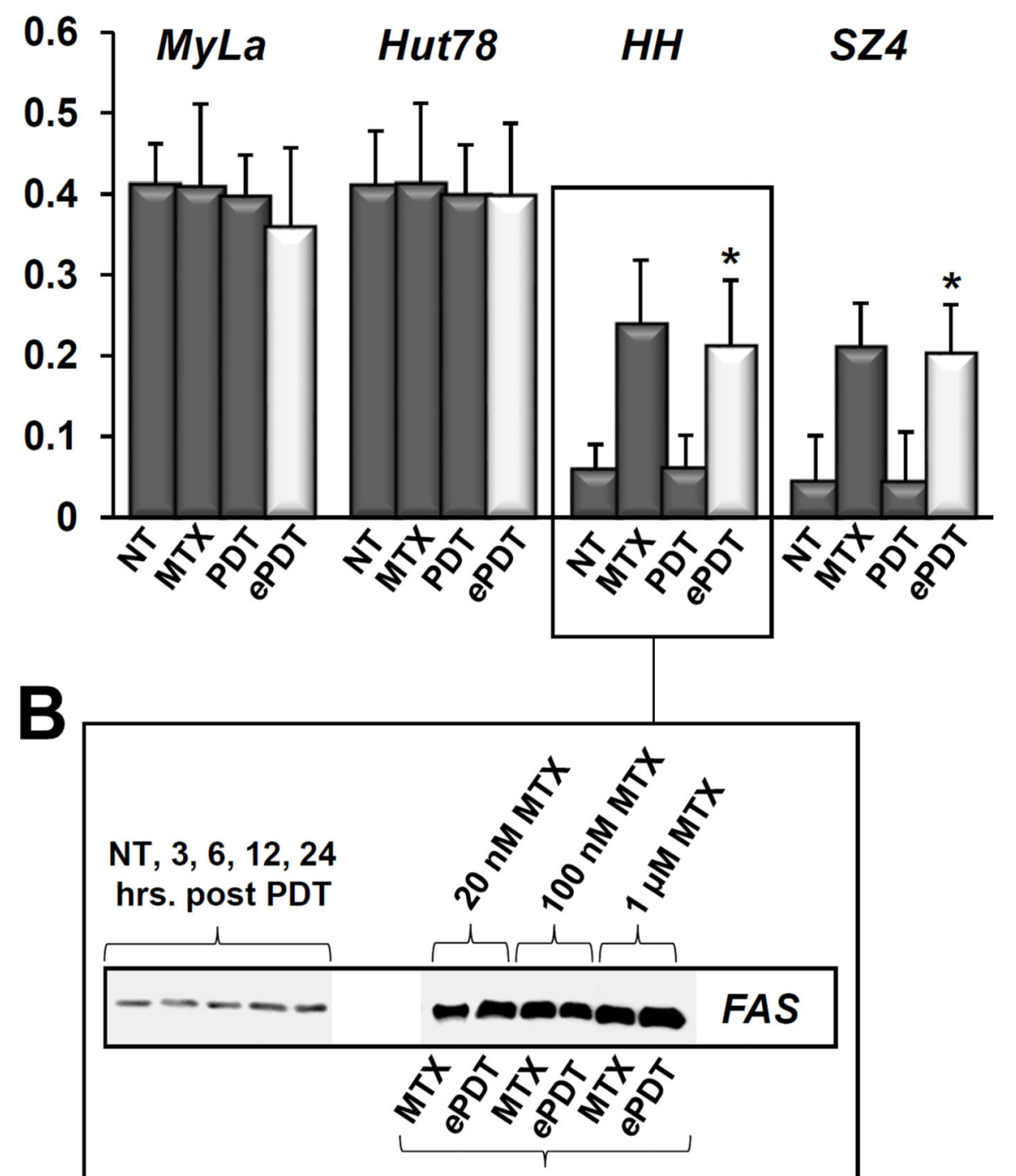

24 hrs. post MTX or ePDT

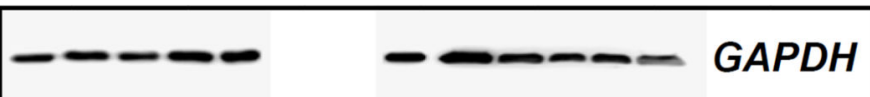

Figure 4.

FAS expression in CTCL cell lines in response to conventional ALA-PDT versus $e$ PDT. A) Quantitative MIA-based assessment of FAS levels in MyLa, Hut78, HH and SZ4 (the FASnull cell line SeAx was omitted from this experiment) in untreated controls (NT), cells post $48 \mathrm{~h}$ incubation with $100 \mathrm{nM}$ MTX, and cells 24 hours after conventional PDT versus $e$ PDT. $* \mathrm{p}<0.01$ as compared to conventional PDT. B) Western blot analysis of FAS expression by HH cells following conventional PDT (lane 1: untreated controls, lanes 2-5: 3, 6, 12 and 24 hours post PDT) versus 24 hours after $e$ PDT. 


\section{FASL, avg. OD/cell}

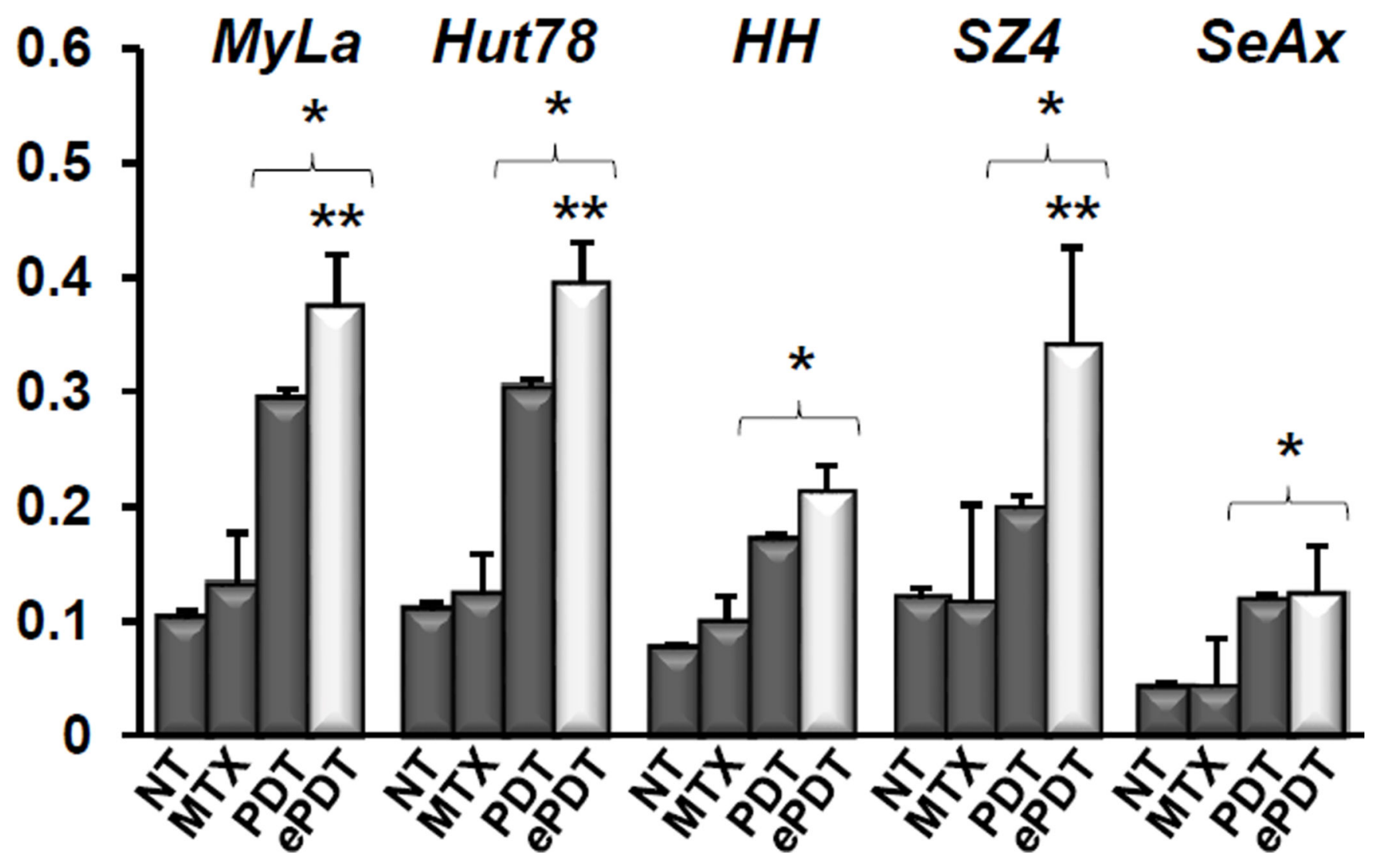

Figure 5.

Quantitative IHC analysis of FASL expression in MyLa, Hut78, HH, SZ4 and SeAx cells: untreated controls (NT), post 48h incubation with $100 \mathrm{nM}$ MTX, 24 hours after conventional PDT, and 24 hours following $e$ PDT. ${ }^{*} \mathrm{p}<0.01$ as compared to untreated controls; **p $<0.01$ as compared to conventional PDT. 
A DR4, avg. OD/cell

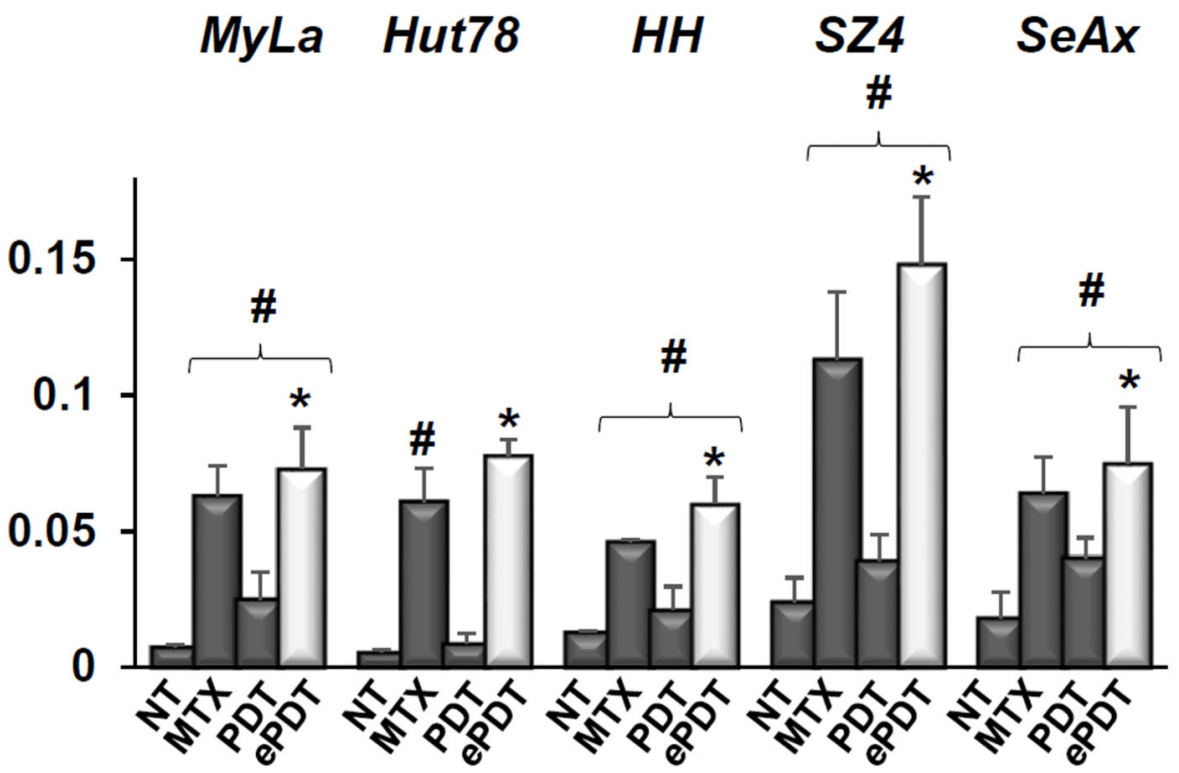

B TRAIL, avg. OD/cell

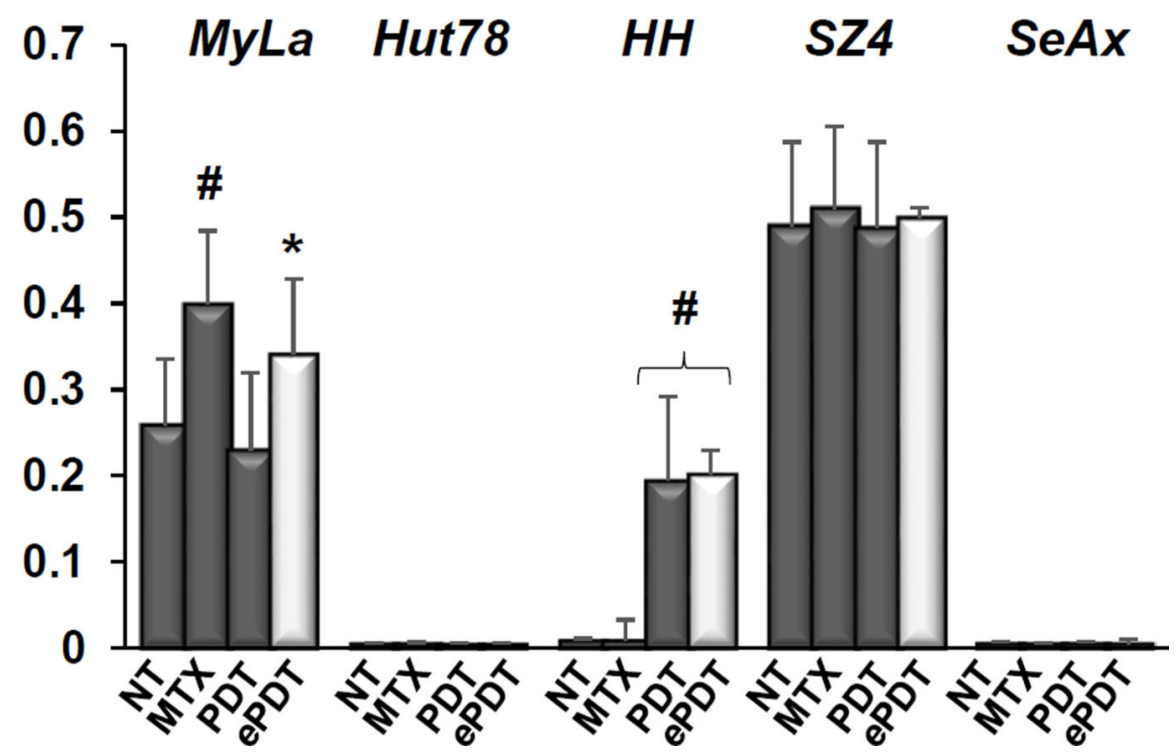

Figure 6.

A) Expression of DR4 in CTCL cell lines as quantitated by MIA, showing untreated controls (NT), cells following $48 \mathrm{~h}$ incubation with $100 \mathrm{nM}$ MTX and 24h after conventional PDT versus $e \mathrm{PDT}$; \# $\mathrm{p}<0.01$ as compared to untreated controls, $* \mathrm{p}<0.01$ as compared to conventional PDT. B) This panel demonstrates MIA-established expression of TRAIL in CTCL cells in the samples described above, with \# $\mathrm{p}<0.01$ as compared to untreated controls and $* \mathrm{p}<0.01$ as compared to conventional PDT. 
A Cleaved caspase 3, avg. OD/cell

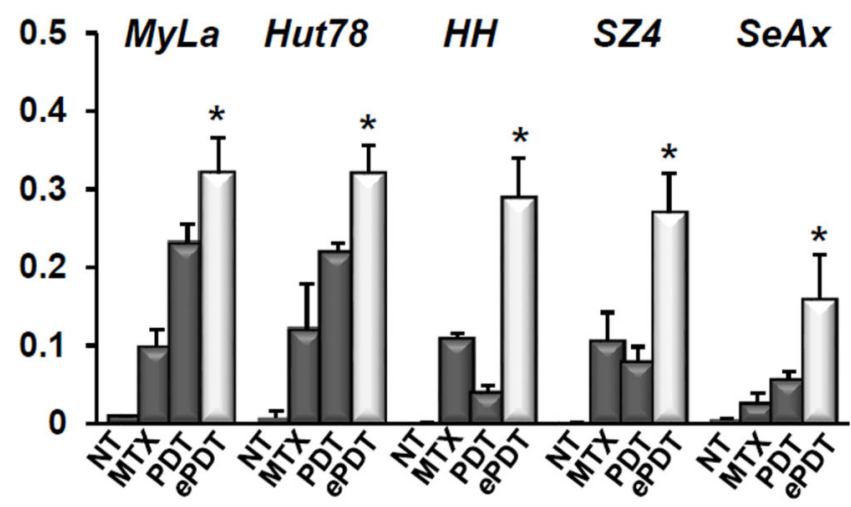

C

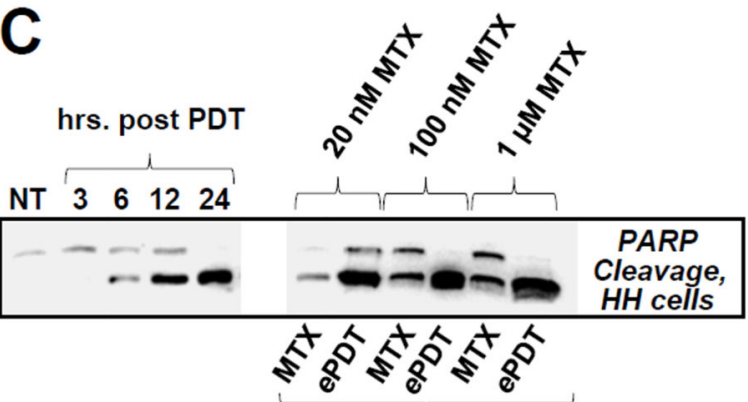

24 hrs. post MTX or ePDT

\section{GAPDH,}

HH cells

Figure 7.

A) Cleaved caspase 3 levels in CTCL cell lines as established by MIA, showing untreated controls (NT), status post $48 \mathrm{~h}$ incubation with $100 \mathrm{nM}$ MTX, and cells 24 hours after conventional PDT versus $e$ PDT; *p $<0.01$ as compared to conventional PDT. B) This panel shows caspase 3 cleavage in FAS-low HH cells after conventional PDT (1: untreated controls, 2-6: cells post conventional PDT at 3, 6, 12, 24 and 48 hours post irradiation) and $e$ PDT using $20 \mathrm{nM}, 100 \mathrm{nM}$ and $1 \mu \mathrm{M}$ MTX (1, 4, 7: MTX only controls; 2, 5, 8: cells 12 hours post $e$ PDT: 3,6 , 9: cells 24 hours following $e \mathrm{PDT})$. *p $<0.01$ as compared to conventional PDT. C) Western blot analysis of PARP/cleaved PARP products in HH cells after PDT (lane 1: untreated controls, lanes 2-5: 3, 6, 12 and 24 hours post PDT) and $e$ PDT (lanes 7, 9, 11: $20 \mathrm{nM}, 100 \mathrm{nM}, 1 \mu \mathrm{M}$ MTX, respectively; lanes 6, 8 and 10 represent MTX only controls). 
A Cleaved caspase 8, avg. OD/cell

0.4 MyLa Hut78 HH SZ4 SeAx

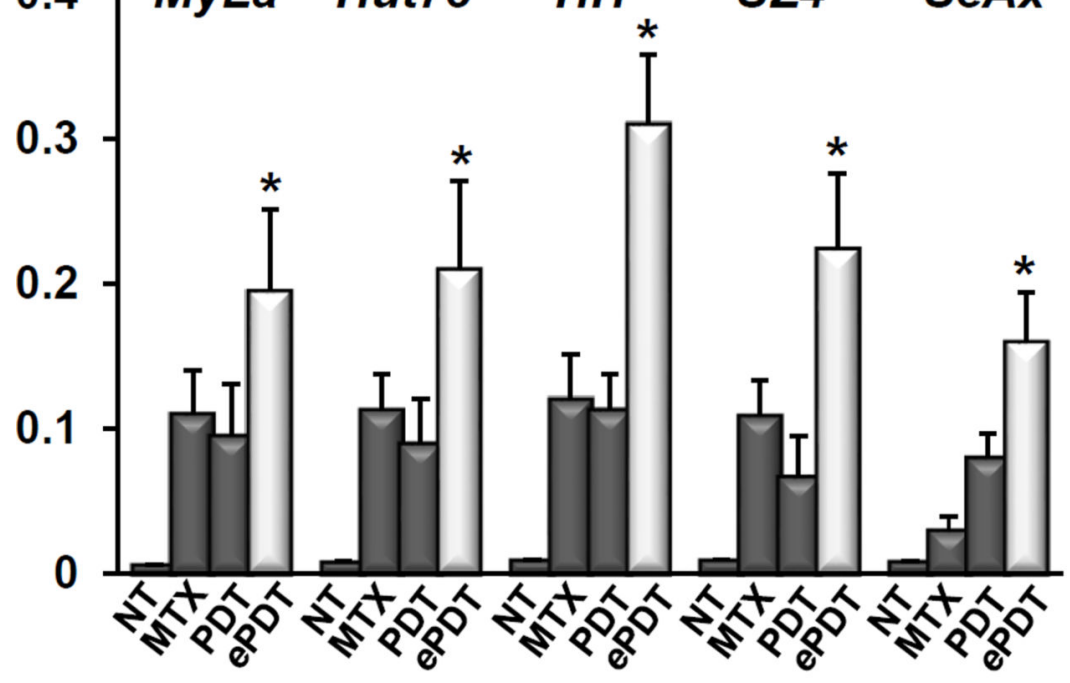

B Cleaved caspase 9, avg. OD/cell

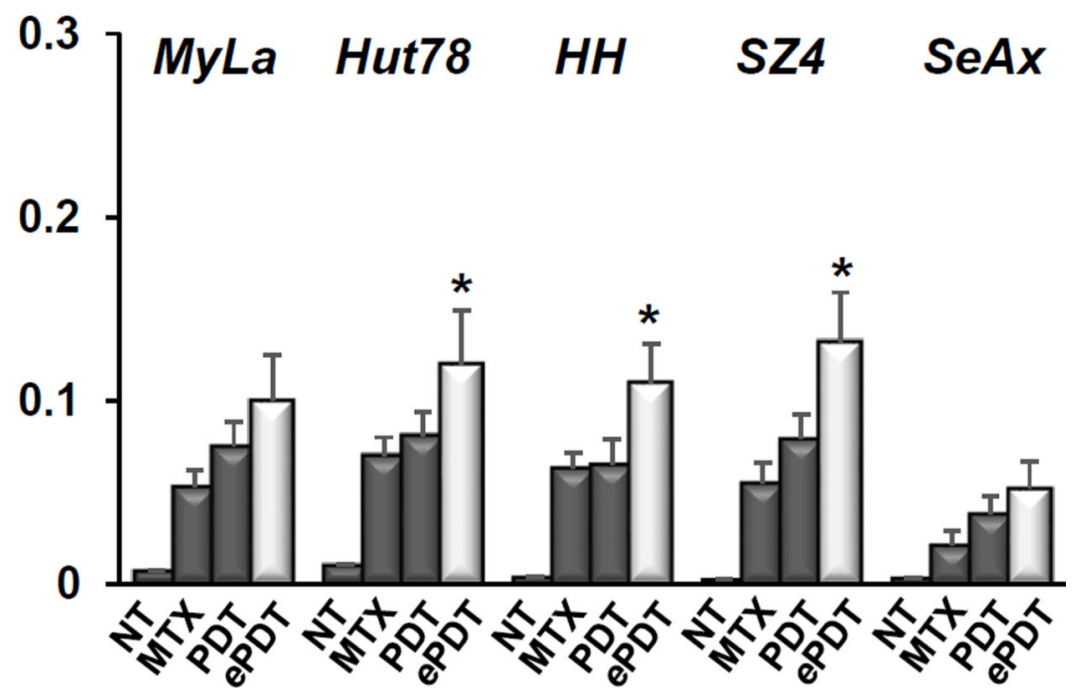

Figure 8.

A) Cleaved caspase 8 levels in CTCL cell lines as quantitated in untreated controls (NT), cells post $48 \mathrm{~h}$ incubation with $100 \mathrm{nM}$ MTX, cells 24 hours after conventional PDT, and cells following $e$ PDT; * $<0.01$ as compared to conventional PDT. B) MIA-based quantitation of cleaved caspase 9 in CTCL cell lines in untreated controls (NT), post 48h incubation with $100 \mathrm{nM}$ MTX, and 24 hours after conventional PDT versus $e$ PDT. *p $<0.01$ as compared to conventional PDT. 


\section{Table 1}

Summary of increases in FAS/FASL- and TRAIL-R1(DR4)/TRAIL expression post epigenetically enhanced photodynamic therapy ( $e$ PDT) as assessed by multispectral imaging analysis. The components of $e$ PDT (methotrexate (MTX) and photodynamic therapy (PDT)) responsible for the increase are listed individually for each cell line.

\begin{tabular}{|c|c|c|c|c|}
\hline CTCL Line & FAS Increase & FASL Increase & TRAIL-R1(DR4) Increase & TRAIL Increase \\
\hline MyLa & $*$ & PDT & MTX, PDT & $*$, MTX \\
\hline Hut78 & $*$ & PDT & MTX & \\
\hline HH & MTX & PDT & MTX, PDT & PDT \\
\hline SZ4 & MTX & PDT & MTX, PDT & $*$ \\
\hline SeAx & $* *$ & PDT & MTX, PDT & \\
\hline
\end{tabular}

CTCL, cutaneous T-cell lymphoma; FAS, Fas cell surface death receptor; FASL, Fas cell surface death receptor ligand; TRAIL-R1(DR4), TRAIL receptor 1 (death receptor 4); TRAIL, tumor necrosis factor-related apoptosis-inducing ligand;

\footnotetext{
*High baseline expression;
}

**

FAS-null. 